\title{
ECONOMIA SOLIDÁRIA E AUTOGESTÃO: DESAFIOS E PERSPECTIVAS NA ÓTICA DE UM APOIADOR DE UMA COOPERATIVA DE RECICLAGEM
}

\author{
Wilson Roberto Lussari \\ Universidade do Oeste Paulista - UNOESTE. Coordenador e Professor do Curso Superior de Tecnologia em Gestão \\ Comercial e Professor dos cursos de Administração, Medicina, Presidente Prudente - SP. E-mail: wlussari@unoeste.br
}

\section{RESUMO}

Esta pesquisa deriva de uma reflexão sobre a necessidade de compreender e de estabelecer um entendimento do porque a Autogestão é uma forma difícil de se aplicar em organizações de catadores de material reciclável. Inicialmente procedeu-se uma pesquisa exploratória sobre o assunto, a qual serviu de referencial para embasar as observações "in loco" do autor ao longo dos últimos oito anos junto à cooperativa, na qualidade de representante de uma das instituições do grupo de apoiadores. O resultado evidencia que a cooperativa tem dificuldade de aplicar a autogestão por um conjunto de fatores, tais como: a inserção da cooperativa no sistema capitalista; a pesada influência dos intermediários do mercado subjugando o desenvolvimento da cooperativa; as limitações organizativas e formativas dos cooperados; as disputas individuais no seio da cooperativa; os limites de esforço do grupo de apoiadores, por mais idealistas que sejam, frente aos objetivos tipicamente capitalistas dos cooperados.

Palavras-chave: Administração, Economia, Autogestão, Reciclagem, Cooperativa

\section{SOLIDARITY ECONOMY AND SELF-MANAGEMENT: CHALLENGES AND PERSPECTIVES FROM A SUPPORTER VIEW OF A WASTE RECYCLING COOPERATIVE}

\begin{abstract}
This research stems from a reflection on a to understand and to establish needs about an understanding of why self-management is a difficult way to apply on recyclable waste pickers organizations. Initially undertook an exploratory research on the subject, which served as a reference to support the past eight years' author "in loco" observations with the cooperative, as a representative of one of the institutions in the group of supporters. The result shows that the cooperative has difficulty applying the self-management of a set of factors such as: the cooperative insertion in the capitalist system; the heavy influence of market intermediaries subduing the cooperative's development; organizational and training constraints of cooperative members; individual disputes within the cooperative; the group of supporters' effort limits, by most idealistic they are, face the goals typically capitalist of cooperative members.
\end{abstract}

Keywords: Management, Economics, Self-management, Recycling, Cooperatives 
Falar de Economia Solidária (ES) também é falar no processo de autogestão. A organização de trabalhadores em qualquer tipo de atividade dentro da ES precisa também incorporar uma forma democrática de gestão, a qual envolve a participação popular de cada um e todos os seus membros. Mas a autogestão não é uma forma fácil de ser implantada.

Não obstante, a própria palavra "autogestão" é divulgada em diferentes tipos de cooperativas, pertencentes a classes sociais distintas e antagônicas, que cada vez mais estão estritamente preocupadas com a viabilidade econômica do empreendimento e com a reprodução do capital, e não com sua função social, de caráter emancipatório em sentido pleno, qual seja, que englobe as dimensões social, econômica e política. (BENINI et al., 2009, p. 77)

Mais do que uma simples palavra a autogestão envolve uma capacidade de aprendizagem simultânea, a qual mutuamente se reforça na prática daquela.

A "auto-educação de iguais" e a "autogestão da ordem social reprodutiva" não podem ser separadas uma da outra. A autogestão - pelos produtores livremente associados - das funções vitais do processo metabólico social é um empreendimento progressivo - e inevitavelmente em mudança. O mesmo vale para as práticas educacionais que habilitem o indivíduo a realizar essas funções na medida em que sejam redefinidas por eles próprios, de acordo com os requisitos em mudança dos quais eles são agentes ativos. A educação neste sentido, é verdadeiramente uma educação continuada. Não pode ser vocacional [...], tampouco "geral”.(MÉSZÁROS, p.74, 2005)

A prática de autogestão exige que os participantes de uma organização aprendam e estejam munidos dos princípios democráticos demandados para se discutir, apresentar e acatar as deliberações que forem necessárias.

A educação continuada, como constituinte necessário dos princípios reguladores de uma sociedade para além do capital, é inseparável da prática significativa da autogestão. Ela é parte integral desta última, com representação no início da fase de formação na vida dos indivíduos, e, por outro lado, no sentido de permitir um efetivo feedback dos indivíduos educacionalmente enriquecidos, com suas necessidades mudando corretamente e redefinidas de modo equitativo, para determinação global dos princípios orientadores e objetivos da sociedade. (MÉSZÁROS, 2005, p. 75)

Mas a autogestão ainda tem um longo percurso a ser percorrido, para conquistar seu espaço como alternativa ao sistema capitalista.

Korosue e Guimarães (2012) fazem uma discussão sobre as bases teóricas do autogestão no socialismo utópico e dos limites uma produção "não capitalista". 
Sua gênese remonta à Revolução Industrial, quando da transição de uma capitalismo comercial para um capitalismo industrial, identificado o momento do "putting-out system" ${ }^{1}$ (MOTTA; PEREIRA, 1986). Neste período o artesão continuava a trabalhar como anteriormente, exceto que o produto de seu trabalho já não Ihe pertence mais. Este passa a pertencer àquele que Ihe adianta as matérias-primas e o salário.

O modo de produção capitalista proporcionou alguns avanços importantes que teriam impacto direto na soberania do produtor. Um foi o controle sobre a produção de tal forma que impôs ao produtor apenas duas opções: submeter-se ou morrer de fome. (MOTTA; PEREIRA, 1986) Assim a grande inovação do sistema fabril foi, de fato, o controle sobre o produtor. Algo que se sofisticou ao longo do tempo, que hoje controla até mesmo a prestação de serviços ou a produção de ideias.

O desenvolvimento do controle sobre a produção passa pela criação de duas atividades novas: a disciplina e a vigilância. (MOTTA; PEREIRA, 1986) A primeira visava o aumento da quantidade pelo aumento do trabalho fornecido. Já a segunda reduzia o salário real, eliminando desvios e fraudes na produção. Assim a acumulação de capital era perseguida pelo controle hierárquico da produção.

A instituição de códigos de fábrica, dava ao capitalista a capacidade de legislar sobre o destino do trabalhador e seu trabalho, na forma de uma caricatura de regulamentação social. (MARX apud MOTTA; PEREIRA, 1986)

Para assegurar que tudo fosse hierarquizado e controlado, a fim de se obter o máximo lucro da produção, institui-se aí a organização burocrática. "A organização burocrática e o controle hierárquico são manifestações concretas da alienação do trabalhador de suas atividades profissionais" (MOTTA; PEREIRA, 1986, p. 300). Mészáros vai além, apontando que a burocratização socializou a alienação em sua forma mais abrangente.

A burocratização monstruosa da sociedade, de acordo com as necessidades de um sistema cada vez mais complexo de produção de mercadorias, conseguiu esvaziar as "instituições democráticas" de toda a sua significação anterior, reduzindo até mesmo o Parlamento [...] à condição de uma associação de debates de segunda categoria, graças ao "consenso" (que equivale de fato, se não necessariamente em intenção, ao "conluio" puro e simples) que predomina em todas as questões de política importantes. (MÉSZÁROS, 2006, p. 275)

\footnotetext{
${ }^{1} \mathrm{O}$ "putting-out system" se caracteriza pela distribuição de matérias-primas a artesãos que posteriormente "venderão" produtos acabados, quando surgem os primeiros sinais de divisão parcelar do trabalho, bem como o momento do sistema fabril, onde se firma a organização centralizada, a disciplina, a cadência de trabalho burocraticamente estabelecida, tornando aos empresários capitalistas mais fácil e garantida a acumulação de capital. (MOTTA; PEREIRA, 1986, p. 295)
} 
Motta e Pereira (1986) argumentam que a organização burocrática é a forma preferida pelos capitalistas:

Os capitalistas preferem a organização burocrática a qualquer outra, porque somente assim poderão controlar a renda obtida na produção, e, além disso, poderão evitar que os trabalhadores adquiram elementos como iniciativa e experiência, para se envolverem numa produção cooperativa própria, ou ainda colocarem em jogo a hegemonia dos capitalistas nos escritórios ou nas próprias fábricas. (MOTTA; PEREIRA, 1986, p. 300)

Entretanto no último quarto do século $\mathrm{XX}$, as metamorfoses dos processos produtivos capitalistas, aliados à desregulamentação das relações de trabalho, acarretou uma significativa mudança em como as relações capital-trabalho se realizavam. As novas técnicas de gestão aumentavam a produção e a produtividade, reduzindo o valor das mercadorias e o valor da força de trabalho. (KOROSUE; GUIMARÃES, 2012)

Para tentar superar a barreira de alienação dentro da organização burocrática, formas engenhosas de democracia industrial capitalista foram concebidas para dar entender que o trabalhador tinha algum poder e autonomia sobre seu trabalho (MOTTA; PEREIRA, 1986, p. 300): participação, cogestão, controle operário e cooperativa.

[...] A cooperativa é uma sociedade voluntária de pessoas que têm como finalidade prestar serviços aos seus associados, sem visar lucros. Contudo, esse seu caráter de criação autônoma dos trabalhadores foi desvirtuado, pois ela passou a ser controlada através de subvenções governamentais, reproduzindo em sua organização real os defeitos do sistema capitalista (pois os trabalhadores passaram a ser seus próprios capitalistas, sobrepujando imperfeitamente o antagonismo capital-trabalho), em vez de questioná-lo e contestá-lo seriamente. (MOTTA; PEREIRA, 1986, p. 303)

Para romper este círculo vicioso do sistema capitalista é que surge como opção a autogestão. Uma forma radical de organização, em forma de uma grande cooperativa, que substituísse o Estado, com a organização direta da vida coletiva em todos os níveis (MOTTA; PEREIRA, 1986).

Para Motta e Pereira a autogestão como organização, percebida por todos como necessária a cada um, não precisa ser imposta, bastando que seus membros se associem por compreender que é o melhor para si. Outro aspecto importante na autogestão é a renovabilidade a cada instante dos dirigentes, para impedir o corte do corpo social em duas categorias: os que comandam e os que obedecem. (MOTTA; PEREIRA, 1986). Também a delegação do poder dá lugar a uma expressão da vontade de todos. 
Complementando estas características, a autogestão tem outro princípio pautado pela compenetração de todos os homens de se determinarem em conhecimento de causa (MOTTA; PEREIRA, 1986). A questão de que o homem foi condicionado à fragmentação do trabalho e a sua consequente alienação, faz com que ele se distancie do sentido de fazer algo. Assim, o homem coletivamente tem uma compreensão do todo, podendo pensar e estabelecer formas decisoriais em larga escala.

Para que isto seja possível há a necessidade de uma mudança social radical, algo também compartilhado por Mészáros.

Com o trabalho emancipado, cada homem torna-se um trabalhador, e trabalho produtivo cessa de ser um atributo de classe. Para esta asserção meramente ser estipula que emancipação implica o compartilhamento universal do trabalho por todos os membros da sociedade, sem definir ao mesmo tempo o significado de "trabalho produtivo" e, talvez mais importante, ignorar a questão de maior gravidade com respeito à fragmentação e a divisão interna do trabalho: a necessariamente e precipitadamente crescente escassez de oportunidades de trabalho dentro da estrutura da economia capitalista e do desenvolvimento tecnológico. (MÉSZARÓS, 1995, p. 928)

Motta e Pereira também relevam que a autogestão da economia não é a descentralização da economia capitalista. É uma revolução, estabelecendo um regime novo que afetaria a sociedade inteira.

Estabelecer a autogestão em uma cooperativa de catadores é um desafio um tanto ambicioso. Mas abdicar de sua viabilidade também precisa colocada de lado, uma vez que a autogestão é uma alternativa a partir de começar uma cooperativa com uma gestão democrática. Como se pode perceber ao longo deste trabalho, o grupo de apoiadores ao longo de sua trajetória esteve exercendo a prática de autogestão constantemente.

Motta e Pereira (1986), apoiando em Guillerm e Bourdet, esclarecem que a autogestão já é uma realidade:

"A autogestão é não somente possível e necessária, mas já está aí, invisível, como é invisível a rotação da Terra". Esta sua presença se faz sentir não só nas reivindicações operárias, mas também nas empresas, ainda que embrionariamente, "a fim de que elas funcionem melhor em beneficio da burguesia". Porém, desta maneira, o operário toma consciência de sua força e capacidade de planejar e executar, [...] e isto pode abrir as possibilidades da derrubada do capitalismo, ou seja o fim das sociedades antagônicas.

Desta forma temos na autogestão uma força latente de transformação, a qual vem sendo construída lentamente, pois a resistência desta sociedade capitalista, e a consequente ameaça ao 
status quo, pode retardar sua ocorrência em larga escala. Mas em questões pontuais, poderíamos inferir que um dos motivos que refreiam o estabelecimento de uma cultura de autogestão dentro da cooperativa, poderia ser a influência dos diversos agentes que interagem com ela, os quais fomentam a competição entre seus pares, seduzindo com ajudas e apoios, os quais nas suas entranhas efetivamente se colocam como atores em defesa do sistema capitalista.

Entretanto, as conclusões de Korosue e Guimarães (2012) apontam que nos estudos realizados por elas em diversas organizações predomina uma proposta idealista de autogestão, que não se aprofunda na objetividade e concretude econômica das organizações, por estar imersa em um sistema capitalista, o que acaba reproduzindo na organização real muitos dos aspectos perversos da organização capitalista do trabalho.

Outra posição a ser refletida é a de Singer (2013) que argumenta que a autogestão não visa apenas uma democratização das relações de produção, mas o seu revolucionamento em profundidade desta mesma sociedade.

Singer (2008) também contribui com uma visão bem realista da atualidade, onde o sucesso de geração de emprego e renda nos Estados Unidos veio exatamente do processo de incorporar os trabalhadores como sócios das empresas. Neste caso a autogestão deriva da necessidade do emprego, de manter aberta a empresa, dos incentivos governamentais, e da inserção e/ou manutenção dentro do modelo capitalista.

Destes, o que diz respeito à cooperativa e aos próprios cooperados reside em como eles próprios se vêem, já que a origem, formação educacional e social influenciam muito seus comportamentos e atitudes externalizados no espaço de trabalho.

[...] os cooperados oscilam em dois extremos, ou se acham empresários e não se preocupam em querer trabalhar tanto quanto os outros, ou se sentem como funcionários não querendo assumir as responsabilidades da cooperativa. (LANZA et al., 2012, p. 201)

Olhando por uma perspectiva menos dramática, temos de compreender que a cooperativa de materiais recicláveis é uma instituição que vai além de um mero local de trabalho e troca. Ela vem no bojo do cooperativismo popular ${ }^{2}$, o qual busca também oferecer uma condição digna e de melhoria social e política ao cooperado.

O objetivo deste trabalho é estabelecer uma compreensão sobre a possibilidade de implantar a Autogestão em uma cooperativa de coletores de materiais recicláveis.

\footnotetext{
${ }^{2} \mathrm{O}$ cooperativismo popular surgiu, se reforça e se expande dentro do contexto de enfrentamentos de modelos econômicos, precisamente reforçando as práticas de economia solidária e trazendo consigo variadas formas de produção, uso e reprodução do capital social, cujos fundamentos básicos são a confiança e ajuda mútua. (OLIVEIRA, 2010, p. 255)
} 


\section{METODOLOGIA}

A metodologia da pesquisa ora elaborada partiu de uma pesquisa exploratória sobre o assunto. Como segundo passo procedeu-se uma reflexão sobre os dados produzidos por meio de observação participante, realizada "in loco" pelo autor ao longo dos últimos oito anos junto à cooperativa, na qualidade de representante de uma das instituições do grupo de apoiadores. Por fim, seguiu-se um estudo de caso, onde as reflexões sobre a cooperativa indicaram sobre a viabilidade e/ou aplicabilidade da autogestão nela.

\section{RESULTADOS}

Apesar de ser factível a aplicação da autogestão em uma cooperativa de reciclagem, os desafios envolvidos quanto ao convencimento das pessoas, e sua consequente mudança de valores e atitudes, faz dela uma realidade quase utópica.

Entretanto, ela é passível de ser alcançada a longo prazo, visto que demanda tanto a conscientização quanto a formação dos integrantes da cooperativa sobre esta forma social de gestão.

\section{DISCUSSÃO}

Deduzimos aqui que a cooperativa de materiais recicláveis teria diversos motivos para inviabilizar a autogestão, entre eles podemos citar alguns: a inserção da cooperativa no sistema capitalista; a pesada influência dos intermediários subjugando o desenvolvimento da cooperativa; as limitações organizativas e formativas dos cooperados; as disputas individuais no seio da cooperativa; os limites de esforço do grupo de apoiadores, por mais idealistas que sejam, frente aos objetivos tipicamente capitalistas dos cooperados.

Enfim, a organização dos trabalhadores de recicláveis poderia ser uma materialização da autogestão que ultrapassa os muros da academia em direção a uma transformação social, mas sua realidade seria a longo prazo, pois não há no momento oportunidade de ruptura do modelo, por depender da solução de convergência de uma série de acontecimentos, listados acima.

\section{CONCLUSÃO}

As reflexões sobre a autogestão são importantes para de serem estudadas melhor, visto que nas formações acadêmicas da área de Administração ainda são periféricas e quase inexistentes. Cabe à academia em primeiro lugar se conscientizar e fomentar estudos continuamente, já que estes abrem a perspectiva de uma forma de gestão organizacional alinhada com as demandas da 
sociedade no presente contexto, por respostas alternativas às limitações do capitalismo frente aos desafios sociais presentes e do futuro próximo.

\section{REFERÊNCIAS}

BENINI, E. G.; FIGUEIREDO NETO, L. F.; BENINI, E. A.; MELO, R. P. DE. Cooperativismo e Autogestão: reflexões sobre a economia solidária. In: DESAFIO: Revista de Economia Administração. Campo Grande, MS, v. 10, n. 21, p. 76-88, mai./ago. 2009.

KOROSUE, A.; GUIMARÃES, V. N. Autogestão e Relações de Trabalho: transformação ou manutenção das condições precárias do trabalho no capitalismo? In: PITAGUARI, S. O.; LANZA, L. M. B.; CORDEIRO, S. A. (Org.) A Sustentabilidade da Economia Solidária: contribuições multidisciplinares. Londrina: UEL, 2012. p. 11-32.

LANZA, F.; BETTIOL, L. M.; SANTOS, L. M. L.; MORAIS, E. E. Poder Público e Economia Solidária na coleta Seletiva e Reciclagem: avanços e desafios da Coopersil em Londrina-PR. In: PITAGUARI, S. O.; LANZA, L. M. B.; CORDEIRO, S. A. (Org.) A Sustentabilidade da Economia Solidária: contribuições multidisciplinares. Londrina: UEL, 2012. p. 191-204.

MÉSZARÓS, I., A Teoria da Alienação em Marx. São Paulo: Boitempo, 2006.

MÉSZARÓS, I., A Educação Para Além do Capital. São Paulo: Boitempo, 2005.

MÉSZARÓS, I., Beyond Capital: toward a theory of transition. London: Merlin Press, 1995

MOTTA, F. C. P.; PEREIRA, L. C. B. Introdução à organização burocrática. 5. ed. São Paulo: Brasiliense, 1986.

OLIVERIA, B. A. M. Significados Acerca das Cooperativas Populares e suas Interfaces com a Economia Solidária. In: FERREIRA, M.A.M.; EMMENDOERFER, M. L.; GAVA, R. Administração Pública, Gestão Social e Economia Solidária: avanços e desafios. Viçosa: UFV, 2010. p. 247-273. SINGER, P. Aprender Economia. São Paulo: Contexto, 25ed 2013.

SINGER, P. Globalização e Desemprego: diagnóstico e alternativas. São Paulo: Contexto, 7ed 2008. 